\title{
High Pressure Nitrogen-infused ultrastable Fuel Cell Catalyst for Oxygen Reduction Reaction
}

\author{
Eunjik Lee, ${ }^{[a]}$ Kurian A. Kuttiyiel, ${ }^{*[b]}$ Kyoung-Hee Kim,[a] Jeongyun Jang,[a] Hyo J. Lee,[a] Jong M.

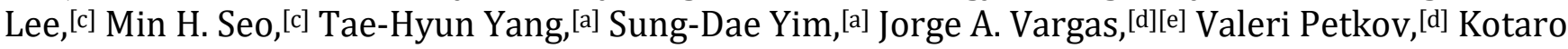 \\ Sasaki, [b] Radoslav R. Adzic, [b] Gu-Gon Park*[a] \\ [a] Fuel Cell Laboratory, Korea Institute of Energy Research, Daejeon 34129, South Korea \\ [b] Chemistry Department, Brookhaven National Laboratory, Upton, NY 11973, USA \\ [c] Fuel Cell Research \& Demonstration Center, Korea Institute of Energy Research, Buan-gun, Jellabuk-do, South Korea \\ [d] Department of Physics and Science of Advanced Materials Program, Central Michigan University, Mt. Pleasant, \\ Michigan 48859, USA
}

[e] Unidad Académica de Física, Universidad Autónoma de Zacatecas, Zacatecas 98098, Mexico

KEYWORDS. core-shell nanostructures, electrocatalyst, fuel cell, nitrogen doping, oxygen reduction.

\author{
Corresponding Authors \\ * Gu-Gon Park (gugon@kier.re.kr) \\ Kurian Kuttiyiel (kurian@bnl.gov)
}

\begin{abstract}
The mass activity of Pt-based catalysts can be sustained throughout the fuel cell vehicle life by optimizing their stability under the conditions of an oxygen reduction reaction (ORR) that drive the cells. Here, we demonstrate improvement in the stability of the readily available PtCo core-shell nanoparticle catalyst over a million cycles by maintaining its electrochemical surface area by regulating the amount of nitrogen doped into the nanoparticles. The high pressure nitrogen-infused PtCo/C catalyst exhibited a two-fold increase in mass activity and a five-fold increase in durability compared with commercial Pt/C, exhibiting retention of $80 \%$ of the initial mass activity after $180 \mathrm{k}$ and maintaining the core-shell structure even after 1000k cycles of accelerated stress tests. Synchrotron studies coupled with pair distribution function analysis reveal that inducing higher amount of nitrogen in core-shell nanoparticles increases the catalyst durability.
\end{abstract}

Materials and Methods.

Synthesis. We prepared the PtCo electrocatalyst using facile one-pot ultrasound-assisted polyol synthesis (UPS). First,

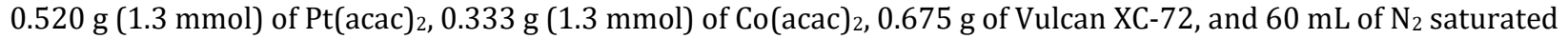
ethylene glycol (EG) were mixed in a $100 \mathrm{~mL}$ glass vial. Thereafter, the precursor suspension in the vial was connected with a horn-type sonicator (Sonic \& Materials, VCX 750 model, tip diameter: $13 \mathrm{~mm}$, solid probe) using a homemade Teflon connector. Then, it was irradiated in a $40 \%$ amplitude condition for $3 \mathrm{~h}$ at $\sim 150^{\circ} \mathrm{C}$. The obtained black slurry was passed through a membrane filter ( $90 \mathrm{~mm}$ diameter, $0.4 \mu \mathrm{m}$ pore size). To remove the residual $\mathrm{EG}$ and prevent ignition of the sample, the filtered sample was washed with ethanol and deionized (DI) water. The filtered sample was placed in a vacuum oven and dried at $70^{\circ} \mathrm{C}$ for $12 \mathrm{~h}$ to attain $1 \mathrm{~g}$ of PtCo/C catalyst. Furthermore, the reproducibility of this process was confirmed by employing it to synthesize $5 \mathrm{~g}$ of nanoparticles without any phase segregation or agglomeration (Table S1).

For the infusion of $\mathrm{N}$ atoms into PtCo NPs, the as-prepared PtCo/C powder was placed in a high-pressure nitriding reactor and annealed at $510^{\circ} \mathrm{C}$ for $2 \mathrm{~h}$. During the annealing step, the pressure of the gas mixture $\left(5.01 \mathrm{~mol} \% \mathrm{NH}_{3}\right.$ and $\mathrm{N}_{2}$ balance) in the furnace was symmetrically controlled from 1 bar to 80 bar to adjust the nitriding levels in the Co core. Based on the elemental composition determined from ICP-EA analysis, the samples were denoted as Pt52Co48/C, Pt53Co45N2/C, Pt44Co42N14/C, and Pt40Co36N24/C.

Electrochemical measurements. Catalyst ink was prepared using $10 \mathrm{mg}$ of electrocatalyst powder dispersed in $2 \mathrm{~mL}$ of solution comprising DI water and isopropyl alcohol (IPA; $\mathrm{v} / \mathrm{v}=4: 1$ ). We placed $5 \mu \mathrm{L}$ of Nafion solution (D521, 
DuPontTM) in the dispersion and sonicated in bath-type sonicator. Finally, $4 \mu \mathrm{L}$ of the catalyst ink was dropped on the glassy carbon electrode $\left(\mathrm{d}=5 \mathrm{~mm}\right.$, area $\left.=0.196 \mathrm{~cm}^{2}\right)$ and dried at room temperature and ambient atmosphere. The Pt loading of the electrodes were maintained at $20.4 \mu \mathrm{g}_{\mathrm{Pt}} \mathrm{cm}^{-2}$. Electrochemical analysis was performed with typical threeelectrode systems coupled with a rotating electrode disk (RDE). The Pt wire and hydrogen reference electrode (Gaskatel GmbH, Germany) were used as the counter and reference electrodes, respectively. The electrocatalyst coated RDE electrode was used as a working electrode. All the potentials in this work are quoted versus a reversible hydrogen electrode (RHE). The cyclic voltammograms (CVs) of each sample were recorded at a scan rate of $20 \mathrm{mV} \mathrm{s}^{-1}$ from 0.03 to $1.1 \mathrm{~V}$ in $\mathrm{N}_{2}$-saturated $0.1 \mathrm{M} \mathrm{HClO}_{4}$. The linear sweep voltammograms (LSVs) for ORR were recorded at a scan rate of $10 \mathrm{mV} \mathrm{s}^{-1}$ and $1600 \mathrm{rpm}$ in the potential range from 0.00 to $1.1 \mathrm{~V} \mathrm{in} \mathrm{O}_{2}$-saturated $0.1 \mathrm{M} \mathrm{HClO}_{4}$. All LSVs curves of samples were corrected by the iR-compensation and the removal of background capacitance current. The accelerated stress test (AST) of each sample was conducted using chronoamperometry at $0.6 \mathrm{~V}$ for $3 \mathrm{~s}$ and $0.95 \mathrm{~V}$ for $3 \mathrm{~s}$.

MEA fabrication and evaluation. To evaluate the MEA performance of the electrocatalysts, the catalyst ink for the anode and cathode were prepared separately. For the anode, $1.0 \mathrm{~g}$ of Pt/C (TKK, TEC10E50E, 46.4 wt.\%) was mixed with ionomer dispersion (Aquivion, D83-24B) in n-propanol (JUNSEI, 99.5\%) and DI water containing solution. The ionomer/carbon (I/C) ratio of the catalyst ink was 0.8 and the ionomer content was $30 \mathrm{wt} . \%$. For the cathode, catalyst ink was prepared using the same procedure but with I/C ratio and ionomer content of 0.6 and 26 wt.\%, respectively. To increase the catalyst ink dispersion, each catalyst ink was mixed by a paste mixer for 30 min and a three-roll mill (Exakt technologies Inc., EXAKT 50I) three times. Thereafter, the catalyst ink for anode was coated on a PET substrate film using a bar coater with a speed of $5 \mathrm{~mm} \mathrm{~s}^{-1}$. In contrast, the catalyst ink for the cathode was directly coated onto a membrane (DuPont Inc., NR211) using an ultrasonic spray (Sono-tek, Accumist $120 \mathrm{kHz}$ ).

After drying at room temperature, the MEAs were fabricated by hot pressing the cathode coated membrane and anode coated PET substrate film at $120^{\circ} \mathrm{C}$ and 30 bar for $20 \mathrm{~min}$. The active area of the MEAs was $25 \mathrm{~cm}^{2}$ and the Pt loading

for both electrodes was fixed as $0.1 \mathrm{mg} \mathrm{cm}^{-2} \mathrm{Pt}$, respectively. The 28BC (SGL carbon Inc.) with the thickness of $235 \mu \mathrm{m}$ was used for the gas diffusion layer. MEA performance of electrocatalysts was evaluated under the following operating conditions in order of anode/cathode electrode: $\mathrm{H}_{2} 400 \mathrm{sccm} / \mathrm{O}_{2} 2000 \mathrm{sccm}, 80{ }^{\circ} \mathrm{C}, 100 \% \mathrm{RH}, 0.5 \mathrm{bar}(50 \mathrm{kPa})$ of backpressure. For conditioning, potential cycling was carried out at $0.4,0.6$, and $0.8 \mathrm{~V}$ for more than $4 \mathrm{~h}$. The currentvoltage (I-V) of MEA was recorded from OCV to $0.6 \mathrm{~V}$ at a scan rate of $10 \mathrm{mV} \mathrm{s}^{-1}$ with a potentiostat (Bio-Logics Science Instruments, HCP-803). The AST of the MEA was carried out using $30 \mathrm{k}$ repeating cycles of chronoamperometry at $0.6 \mathrm{~V}$ for $3 \mathrm{~s}$ and $0.95 \mathrm{~V}$ for $3 \mathrm{~s}$ under the cell operation conditions of the order of anode/cathode: $\mathrm{H}_{2} 200 \mathrm{sccm} / \mathrm{N}_{2} 75 \mathrm{sccm}$, $80{ }^{\circ} \mathrm{C}, 100 \% \mathrm{RH}$.

Characterization. The crystalline structures of all samples were investigated by X-ray diffraction (XRD, Rigaku DMAX$2500, \mathrm{Cu} \mathrm{k} \alpha, \lambda=1.5406 \AA$ ). The nitrogen content of samples was verified using an elemental analyzer (FlashEA 1112, ThermoFinnigan). The compositions and Pt loadings of the samples were determined by inductively-coupled plasma atomic emission spectroscopy (ICP-AES, Thermo Scientific Co./iCAP 6300 Duo). The electronic structures of the samples were investigated by XPS (K-alpha, Thermo VG Scientific). Microscopic studies were conducted using field emission transmission electron microscopy (FM-TEM, FEI, Talos F200X, $200 \mathrm{kV}$ ) and Cs-corrected FE-TEM (JEOL, JEMARM200F, $200 \mathrm{kV}$ ).

In situ X-ray absorption spectroscopy (XAS) measurements were carried out at the ISS Beamline (8-ID) in NSLS-II, Brookhaven National Laboratory. The working electrode consists of the PtCo/N and N-PtCo/C catalyst on a carbon fiber paper that acted as a catalyst support. The working electrode was placed behind a thin Mylar film (10 $\mu \mathrm{m})$ that covered a window of the cell. The electrode was in contact with a $0.1 \mathrm{M} \mathrm{HClO}_{4}$ bulk solution $(\sim 15 \mathrm{~mL})$ in a plastic container. A leak-free $\mathrm{Ag} / \mathrm{AgCl}$ electrode was used as a reference electrode, although the potentials presented for the XAS data are quoted versus a RHE. The fluorescence detector was used to acquire data, which was all then processed using the Athena software ${ }^{1}$.

High-energy synchrotron diffraction experiments were conducted at the 11-ID-C beamline at the Advanced Photon Source, Argonne National Laboratory. X-rays with energy of $105.7 \mathrm{keV}$ were used. The samples were measured sealed in glass capillaries and data were collected to diffraction vectors as high as $27 \mathrm{~A}^{-1}$.

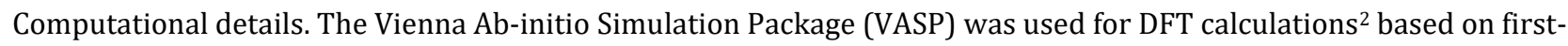
principle calculations. The interaction of core electrons was replaced by the project augmented wave (PAW) pseudopotential $^{3}$. The electron exchange-correlation energy was described by the Perdew, Burke, and Ernzerhof (PBE) functional $^{4}$, which employs the spin-polarized generalized gradient approximation (GGA) ${ }^{5}$. Kohn-Sham wave functions of valence electrons were expanded on a plane-wave basis set with a cut-off energy of $520 \mathrm{eV}$. Before designing the PtCo nanoparticles in 10 bar of $\mathrm{NH}_{3}\left(28.3\right.$ bar at $773 \mathrm{~K}$ ), the cuboctahedral $\mathrm{Pt}_{12} \mathrm{Co}_{1}$ nanoparticle fully relaxed in a vacuum unit cell of a cubic box having $16 \times 16 \times 16 \AA$ dimensions and used in $(1 \times 1 \times 1) \mathrm{k}$-points of the gamma point mesh. After geometrical relaxation of each PtCo nanoparticle and $\mathrm{NH}_{3}$ molecule, PtCo nanoparticles were designed adjacent to each other in cubic boxes of $17 \times 12 \times 12 \AA . \mathrm{NH}_{3}$ molecules were packed under vacuum conditions in the unit cell box, including PtCo nanoparticles via the Monte Carlo simulation method, after assigning a traditional COMPASSII force field using the Amorphous Cell module of Accelers Software Inc ${ }^{6}$. Finally, AIMD simulations ${ }^{7}$ were carried out to ob- 
serve the formation of PtCoN nanoparticles for a time period of 6,000 fs, and the canonical ensemble ${ }^{7}$ was used at 783 $\mathrm{K}$. The models created to reproduce the experimental PDFs were based on the FCC structure including the N atoms in the interstitial octahedral sites. Classical molecular dynamics was carried out at room temperature using force fields in LAMMPS. Thereafter, when the model reproduced an acceptable experimental PDF, it was further refined using the reverse Monte Carlo technique. The strains of the superficial Pt atoms and their coordination numbers were obtained from the refined models. It have to note that the AIMD simulation were performed in limited number of atoms because typical spatial and temporal scales achievable by DFT are restricted to less than ca. 300 atoms and 10 ps. $^{8}$

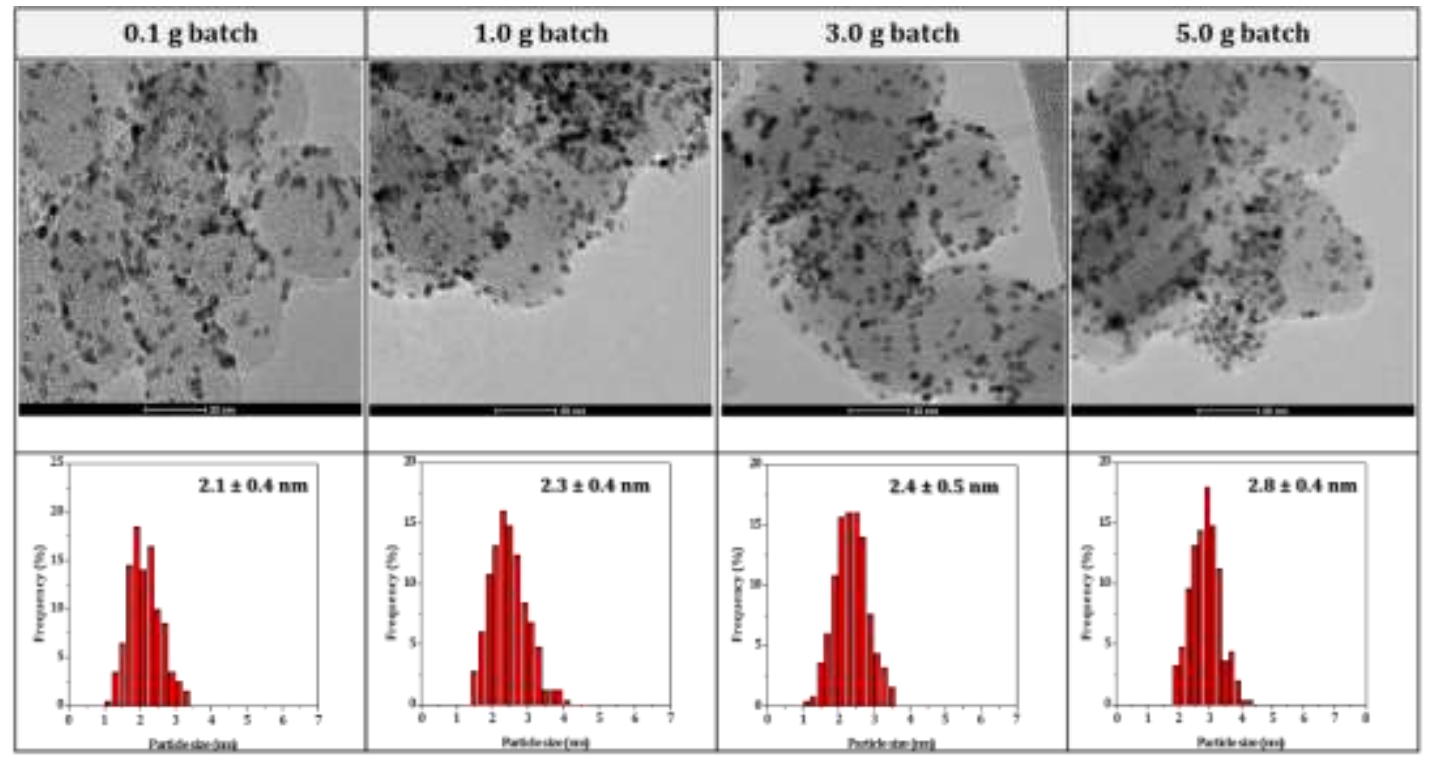

Fig. S1. Transmission electron microscopy images of various batches of synthesized $\mathrm{PtCo} / \mathrm{C}$ and the corresponding particle size histograms. 

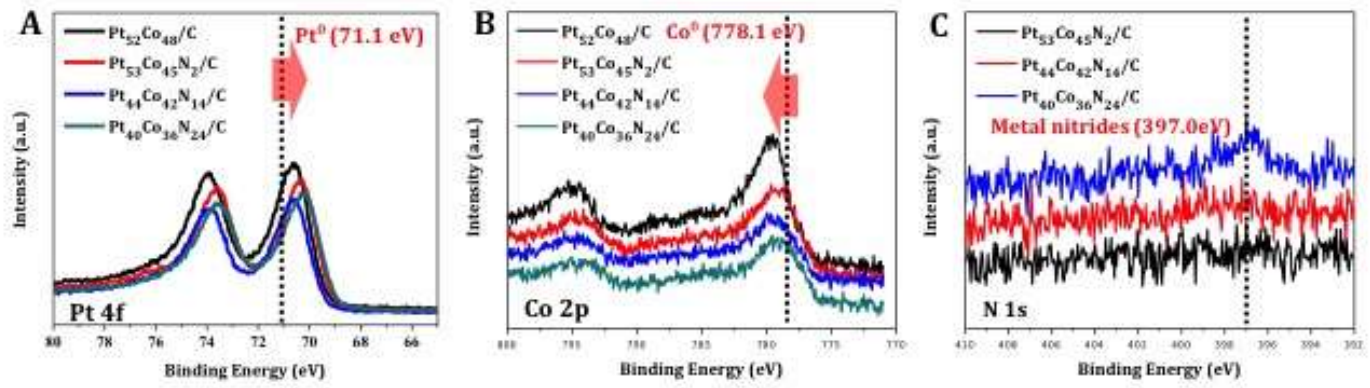

Fig. S2. X-ray photoelectron spectroscopy data of samples in the (a) Pt4f, (b) Co2p, and (c) N1s regions. 


\section{A. PtCo in 1 bar of $\mathrm{NH}_{3}$}

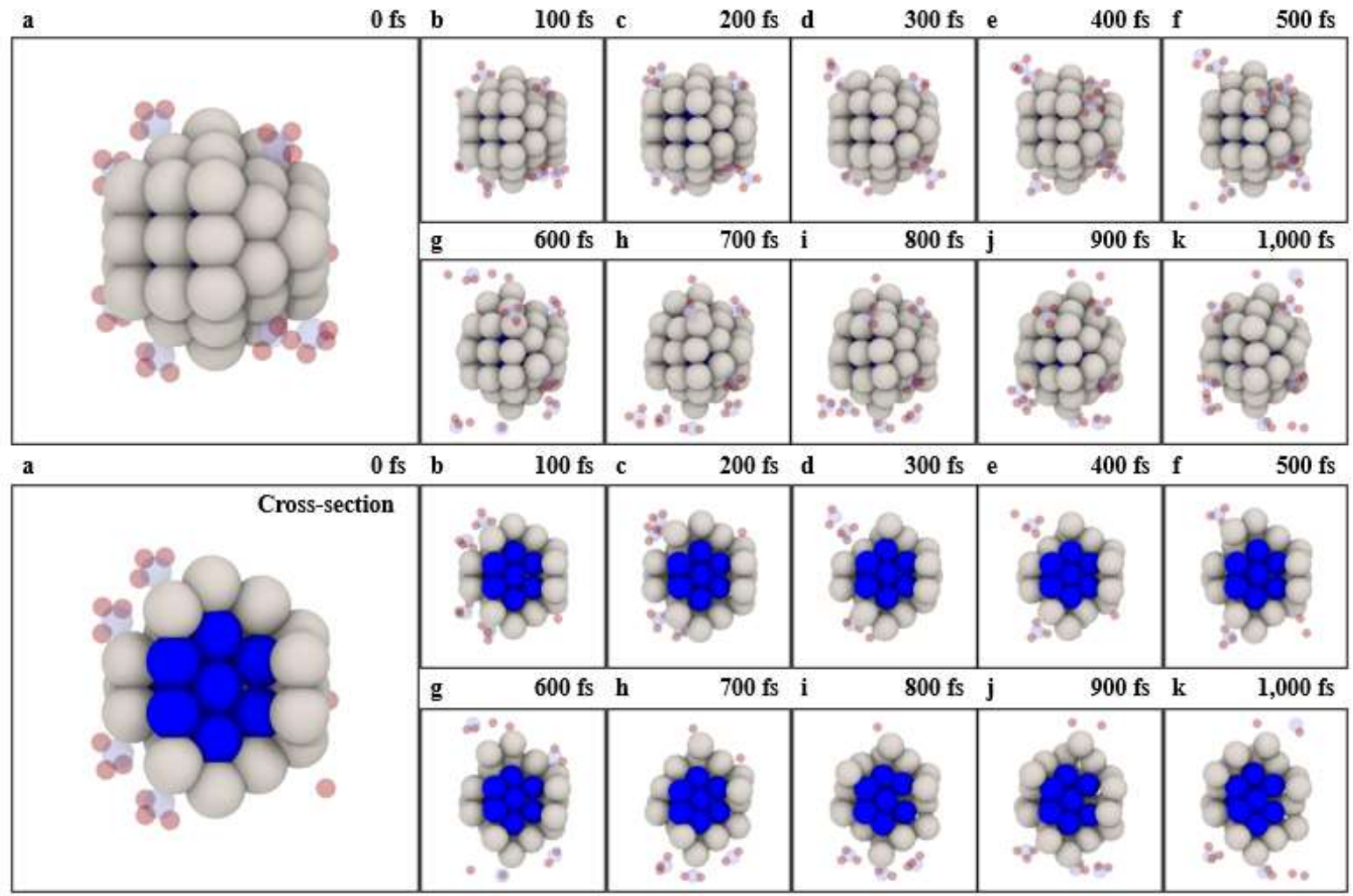

\section{B. PtCo in $10 \mathrm{bar}$ of $\mathrm{NH}_{3}$}

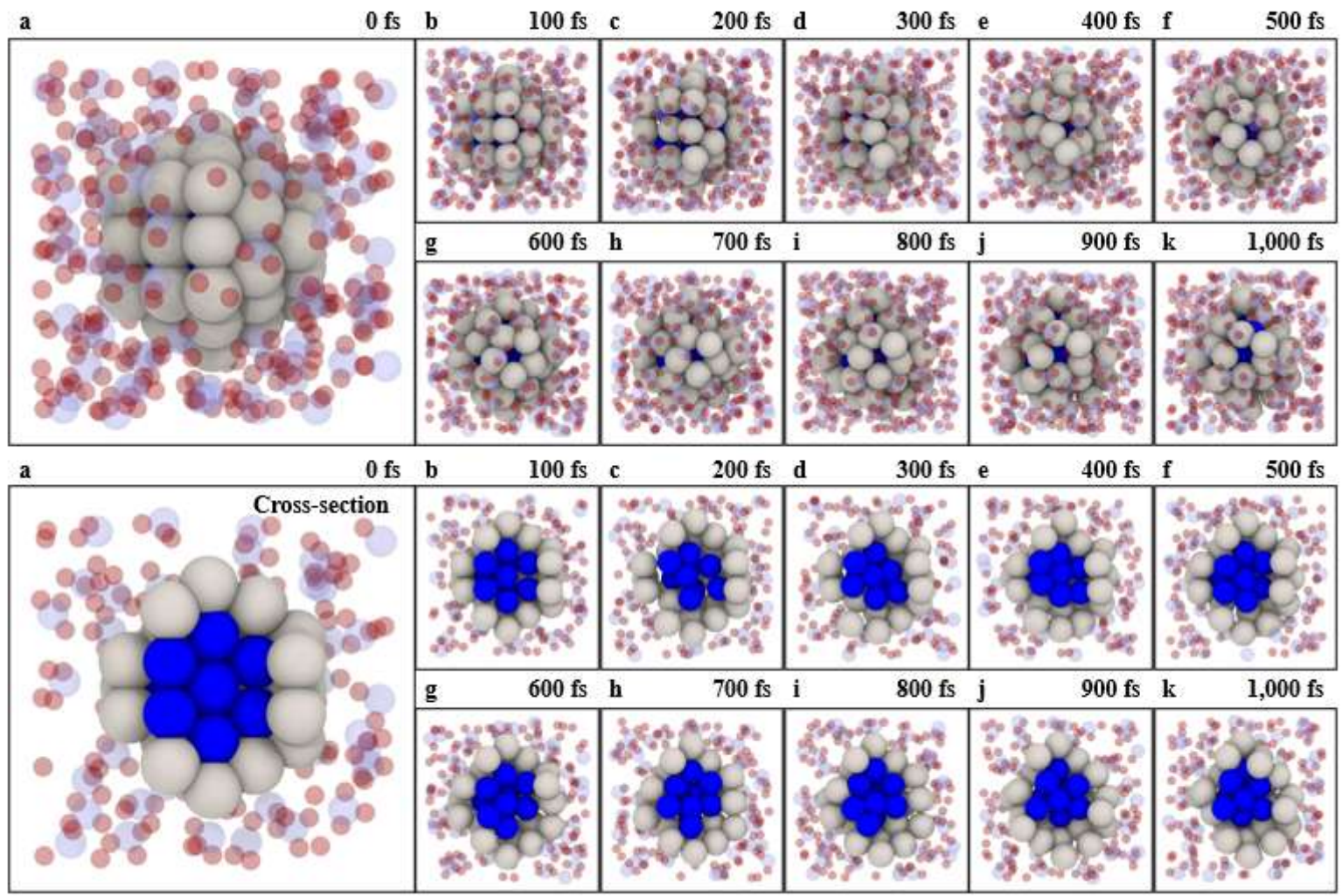




\section{PtCo in 45bar of $\mathrm{NH}_{3}$}

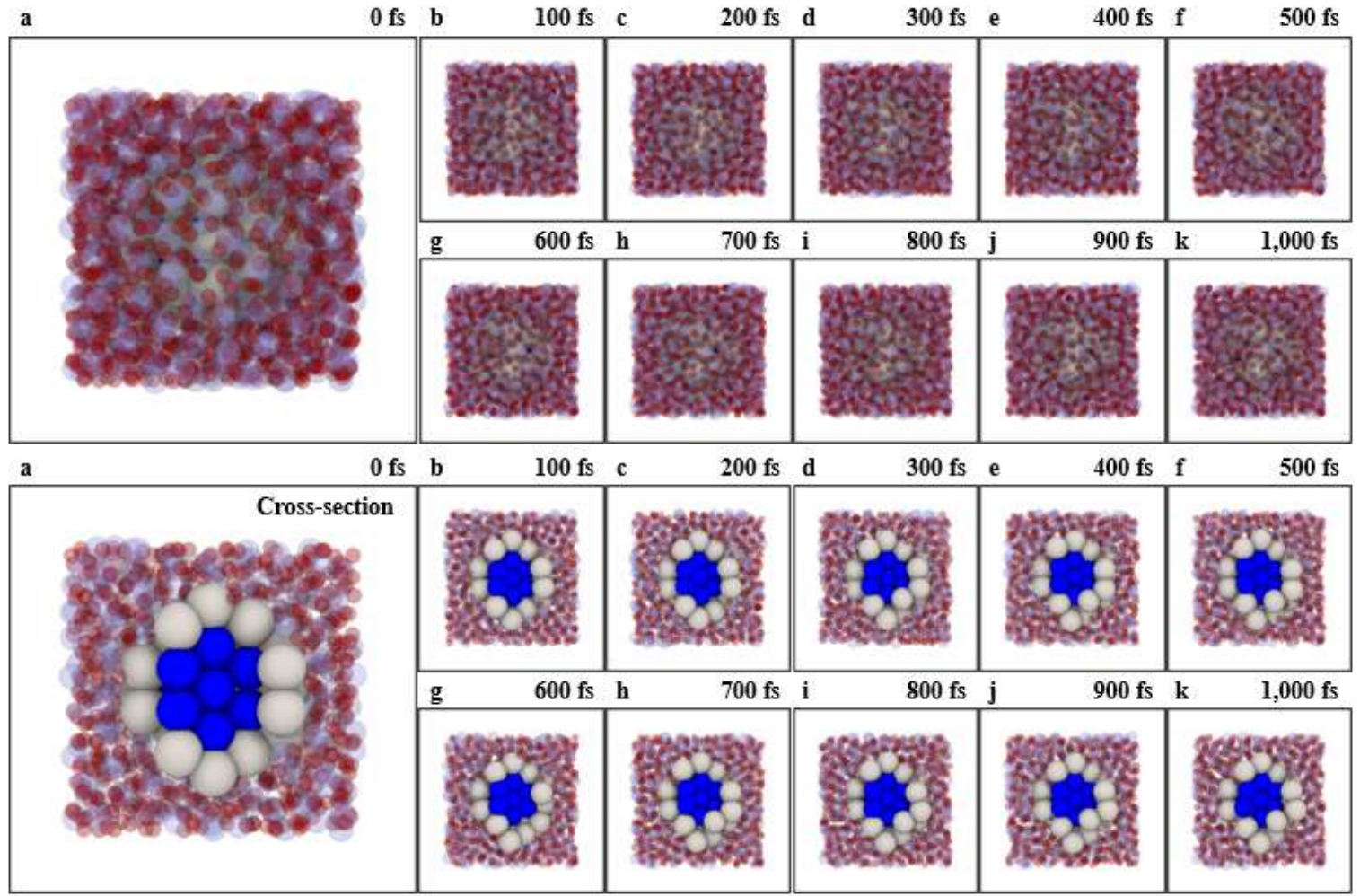

Fig. S3. Original (upper) and cross-sectional (below) images obtained through ab-initio molecular dynamics simulation for PtCo nanoparticles at pressures of (A) 1, (B) 10, and (C) 45 bar of $\mathrm{NH}_{3}$ (See supplementary video clip). 

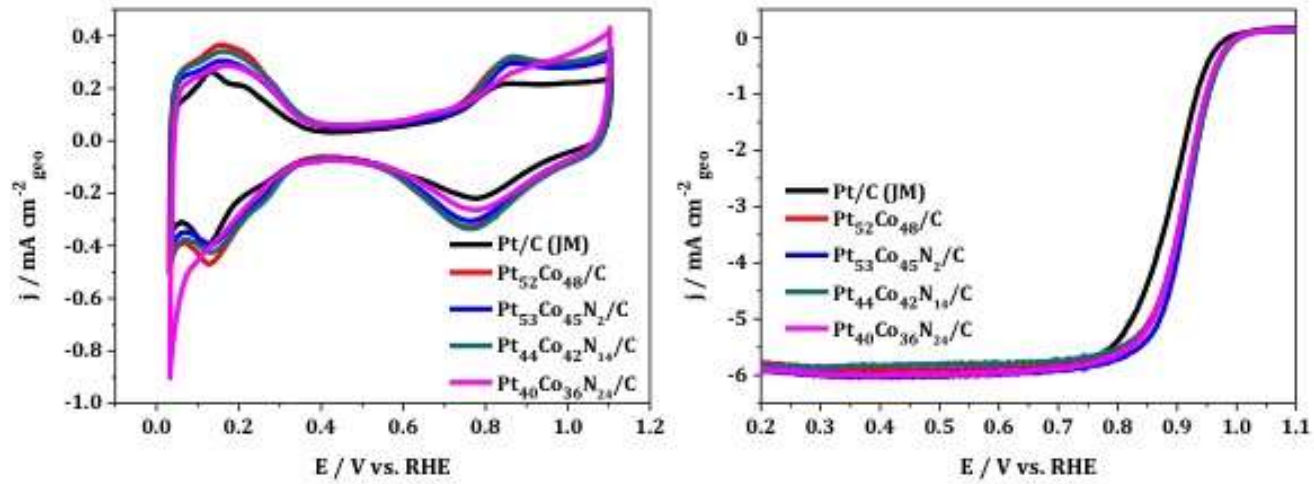

Fig. S4. Cyclic voltammograms (CVs) and linear sweep voltammograms (LSVs) at $1600 \mathrm{rpm}$ for various samples in $0.1 \mathrm{M}$ $\mathrm{HClO}_{4}$. 

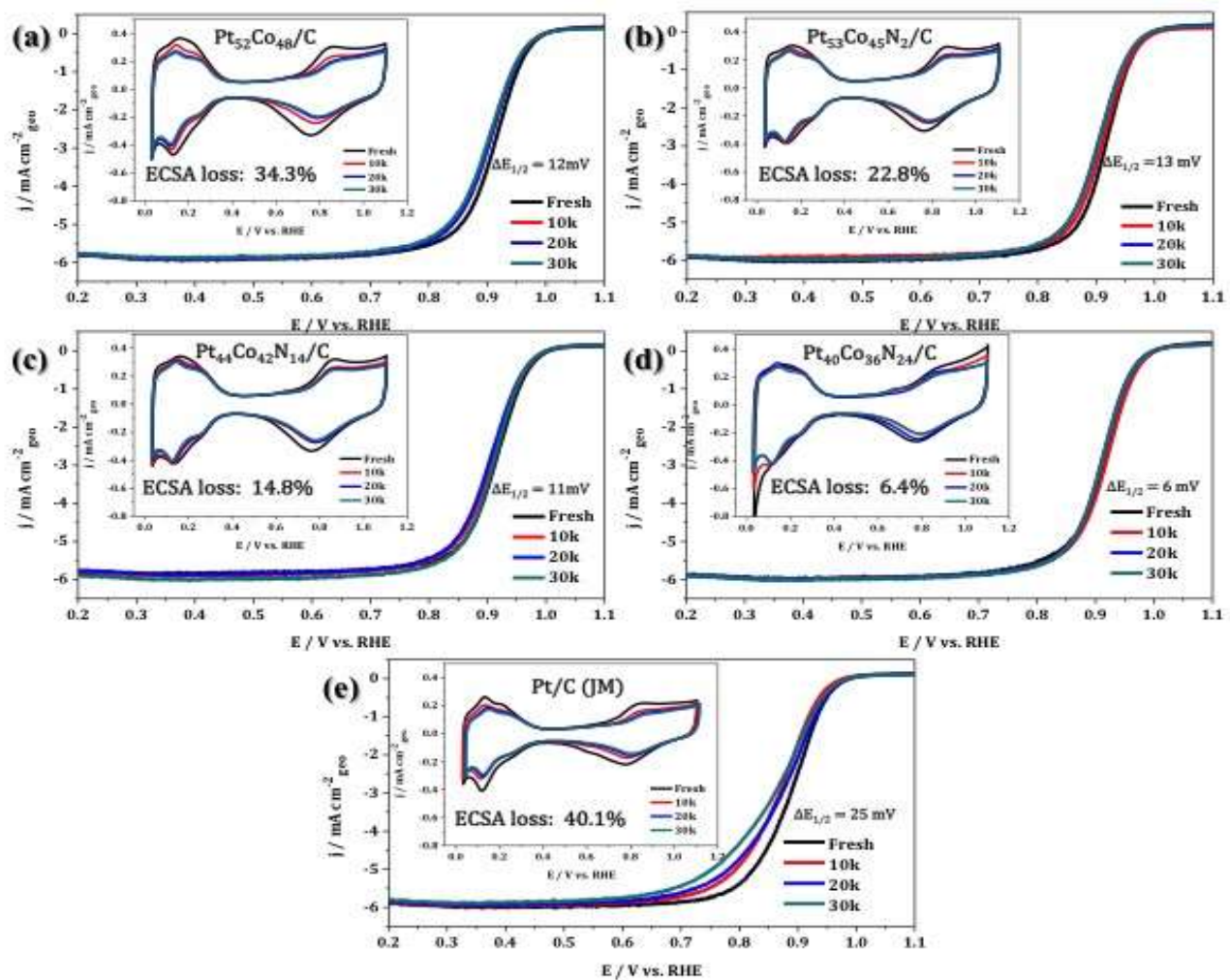

Fig. S5. LSVs of the samples before and after $30 \mathrm{k}$ cycles of accelerated stress test (AST) in $\mathrm{O}_{2}$-saturated $0.1 \mathrm{M} \mathrm{HClO}_{4}$. Inset shows the CVs before and after AST 30k. 

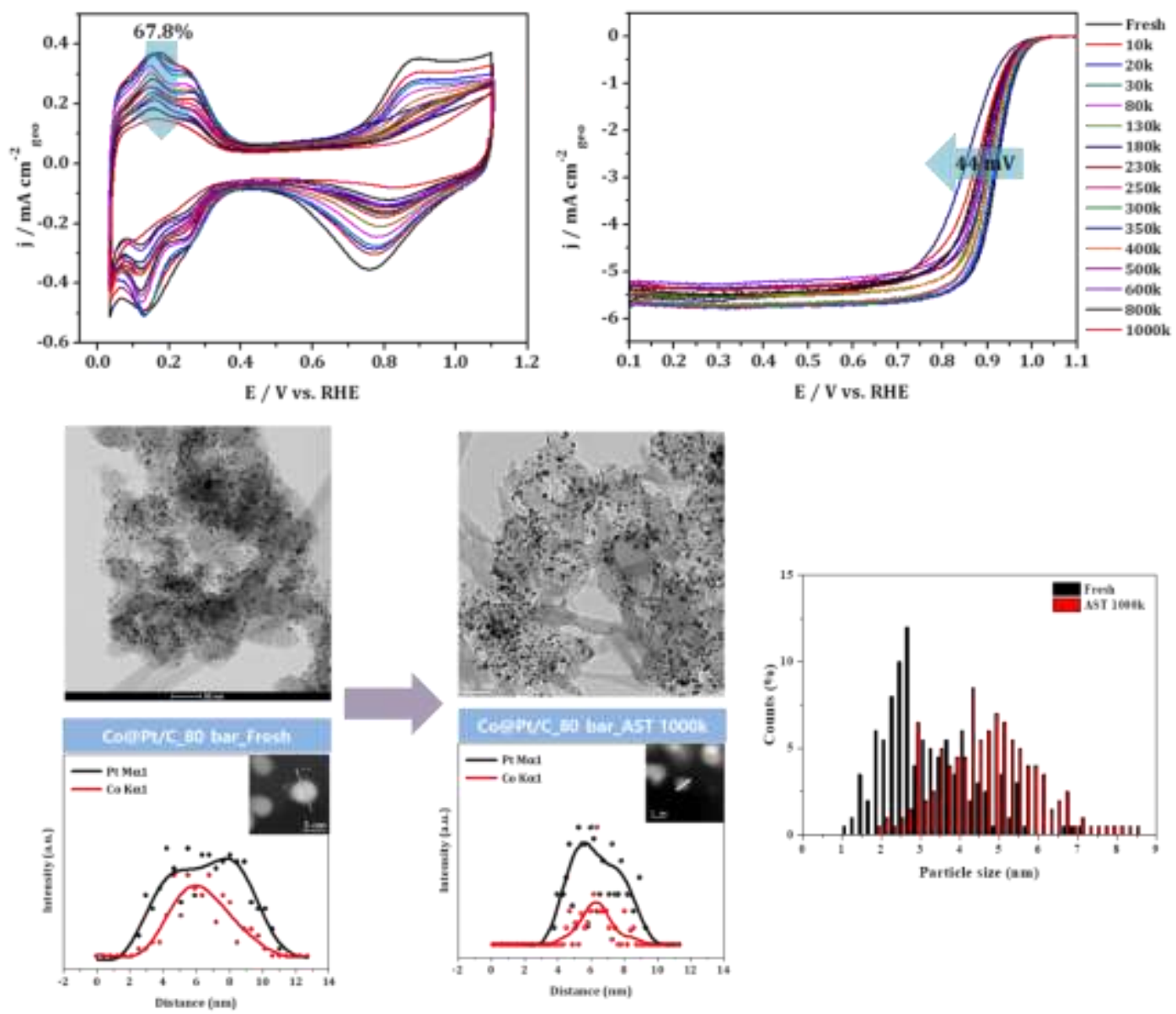

Fig. S6. CVs, LSVs, and TEM images of the $\mathrm{Pt}_{40} \mathrm{Co}_{36} \mathrm{~N}_{24} / \mathrm{C}$ catalyst during $1000 \mathrm{k}$ AST cycles. 

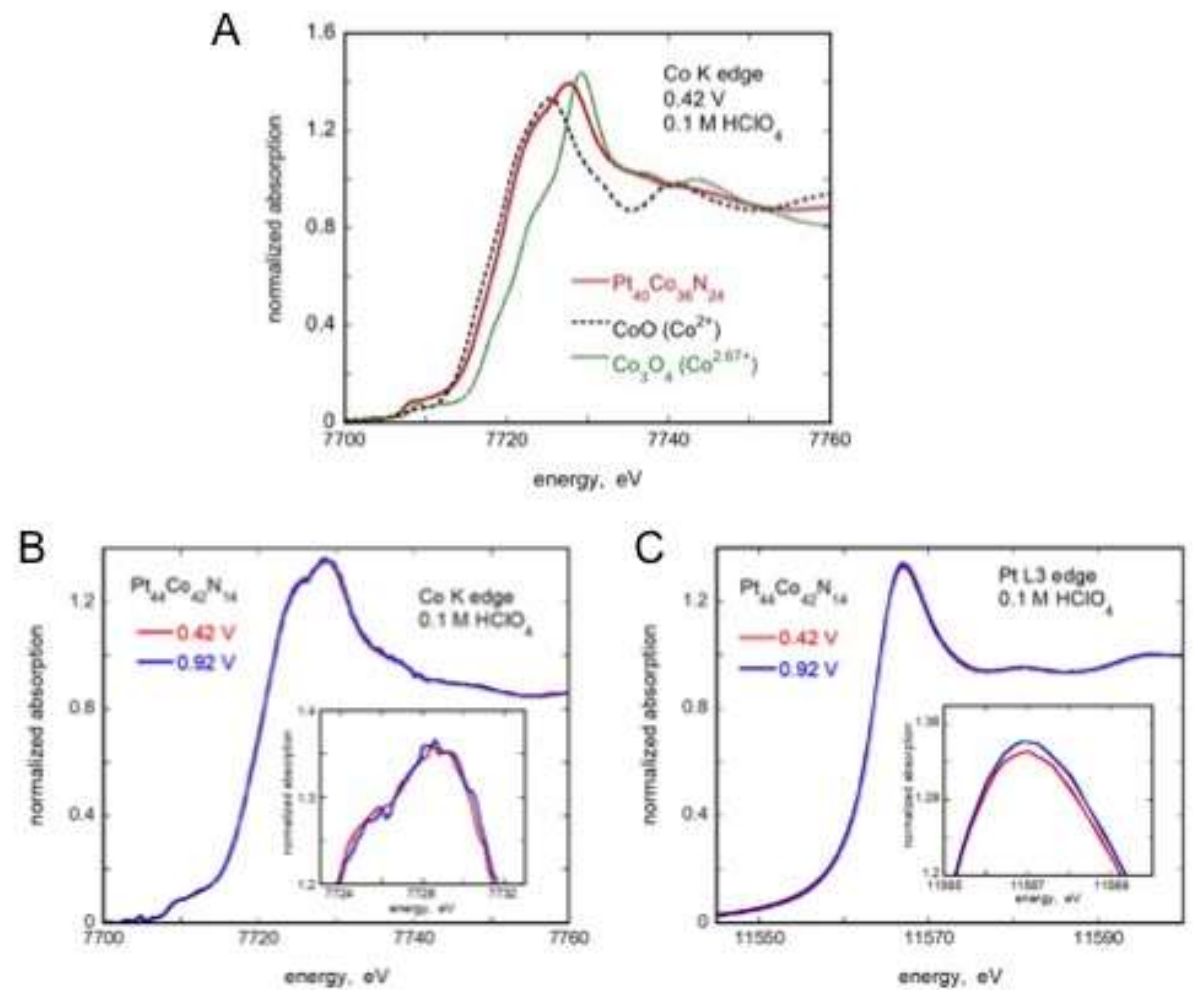

Fig. S7. (A) In situ Co K-edge X-ray absorption near-edge structure (XANES) spectra of the $\mathrm{Pt}_{40} \mathrm{Co}_{36} \mathrm{~N}_{24} / \mathrm{C}$ catalyst measured in $0.1 \mathrm{M} \mathrm{HClO}_{4}$ at a potential of $0.42 \mathrm{~V}$. The ex situ XANES spectra of $\mathrm{CoO}$ and $\mathrm{Co}_{3} \mathrm{O}_{4}$ are also included. In situ XANES spectra of (B) Co K edge and (C) Pt L3 edge of the $\mathrm{Pt}_{44} \mathrm{Co}_{42} \mathrm{~N}_{14} / \mathrm{C}$ catalyst in $0.1 \mathrm{M} \mathrm{HClO}_{4}$ at potentials of $0.42 \mathrm{~V}$ and $0.92 \mathrm{~V}$. The insets present details of the first peaks for the both edges. The intensity of the Pt L3 while line of the catalyst slightly increases with an increased potential at $0.92 \mathrm{~V}$ due to the oxide formation on the Pt surface (Fig. S7C). However, no obvious changes of Co K-edge XANES are observed at potentials of 0.42 and $0.92 \mathrm{~V}$, suggesting that Co atoms in the core are inhibited from oxidation due to the Pt shell. 


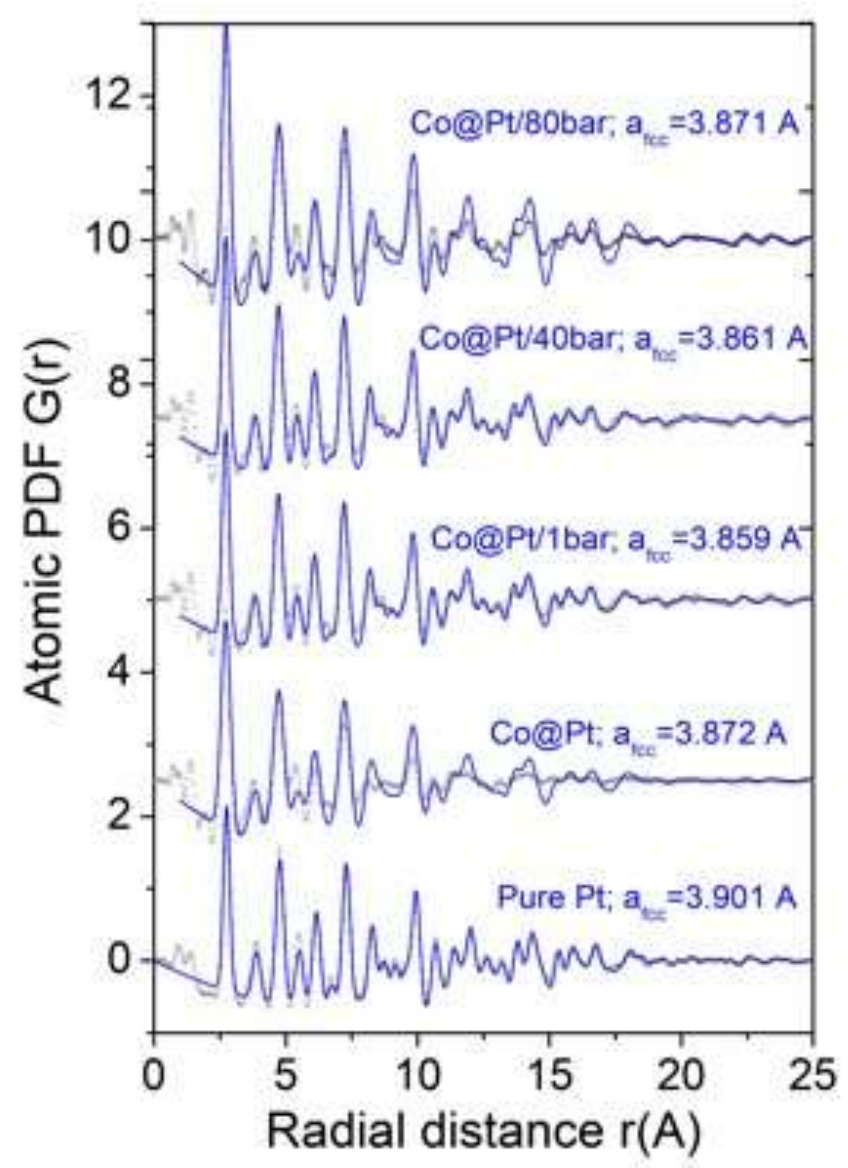

Fig. S8. Experimental (black circles) and RMC model fitting (blue line) atomic pair distribution functions. 
Table S1. Physicochemical properties of various batches of synthesized PtCo/C core-shell samples.

\begin{tabular}{c|c|c|c|c|c}
\hline \multirow{2}{*}{ Batch (g) } & \multicolumn{2}{|c|}{ Particle size (nm) } & \multicolumn{2}{c|}{ Composition (at.\%) } & \multirow{2}{*}{$\begin{array}{c}\text { Pt loading } \\
(\%)\end{array}$} \\
\cline { 2 - 5 } & XRD & TEM & Pt & Co & \\
\hline 0.1 & 1.8 & 2.1 & 52.1 & 47.9 & 25.7 \\
\hline 1 & 2.0 & 2.3 & 52.2 & 47.8 & 24.0 \\
\hline 3 & 1.9 & 2.4 & 59.9 & 40.1 & 24.8 \\
\hline 5 & 2.2 & 2.8 & 62.8 & 37.2 & 25.2 \\
\hline AVERAGE & $2.0 \pm 0.2$ & $2.4 \pm 0.3$ & $56.8 \pm 5.4$ & $43.2 \pm 5.4$ & $24.9 \pm 0.7$ \\
\hline
\end{tabular}




\section{ACKNOWLEDGMENT}

This study was supported by the Industrial Strategic Technology Development Program (NP2020-0040) funded by the Ministry of Trade, Industry \& Energy (MOTIE, Korea) and the Korea Institute of Energy Research (C1-2417). The Fuel Cell Research \& Demonstration Centre acknowledges support from a National Research Foundation of Korea Grant funded by the Korean Government [NRF-2017R1D1A1B04031539]. This manuscript has also been authored by employees/guests of Brookhaven Science Associates, LLC under Contract No. DE-SC0012704 with the U.S. Department of Energy. This research used resources of the ISS (8-ID) and QAS (7-BM) beamlines of the National Synchrotron Light Source II, which are U.S. DOE Office of Science Facilities, at Brookhaven National Laboratory under Contract No. DE-SC0012704 and this study was also supported in part by "DE-SC0006877 grant. The authors declare no competing interests.

\section{REFERENCES}

1. Ravel, B.; Newville, M. J. Synchrotron. Radiat. 2005, 12, 537-541.

2. Kresse, G.; Furthmüller, J. Phys. Rev. B 1996, 54, 11169.

3. Blöchl, P. E. Phys. Rev. B 1994, 50, 17953.

4. Perdew, J. P.; Burke, K.; Ernzerhof, M. Phys. Rev. Lett. 1996, 77, 3865.

5. Kresse, G.; Furthmuller, J. Comput. Mater. Sci. 1996, 6, 15-50.

6. Guo, S.; Li, H.; Li, Y.; Han, Y.; Chen, K.; Xu, G.; Zhu, Y.; Hu, X. Adv. Energy Mater. 2018, 8.

7. Kresse, G.; Hafner, J. Phys. Rev. B 1993, 47, 558.

8. Behler, J.; Parrinello, M., Phys Rev Lett 2007, 98 (14), 146401. 